\title{
EVALUASI KESESUAIAN LAHAN PERTANAMAN KAKAO DI DESA PENYANDINGAN KECAMATAN PUNDUH PIDADA KABUPATEN PESAWARAN
}

\author{
Bagja Rudhia Ulil Albab, Ali Kabul Mahi, Rusdi Evizal \& Tamaluddin Syam \\ Jurusan Agroteknologi, Fakultas Pertanian Universitas Lampung \\ Jl. Prof. Dr. Soemantri Brodjonegoro no. 1 Bandar Lampung 35145 \\ Email:Bagjarudhiaulilalbab@ymail.com
}

\begin{abstract}
ABSTRAK
Tanaman kakao merupakan salah satu tanaman yang penting bagi perekonomian desa Penyandingan Kabupaten Pesawaran, hal ini dikarenakan sumber pendapatan utama mereka berasal dari bertani kakao. Penelitian dilaksanakan pada sebagian lahan pertanaman kakao (Theobroma cacao L) di Kelompok Tani Sumber Rezeki Desa Penyandingan, Kecamatan Punduh Pidada Kabupaten Pesawaran pada bulan Juni 2013. Tujuan dari penelitian ini adalah megevaluasi kesesuaian lahan pertanaman kakao secara kualitatif dan kuantitatif .Evaluasi kesesuaian lahan kualitatif dilakukan berdasarkan persyaratan tumbuh tanaman kakao menurut kriteria Djaenudin dkk. (2000), dan evaluasi kesesuaian lahan kuantitatif dilakukan adalah menganalisis kelayakan finansial dengan menghitung NPV, Net B/C, IRR, dan BEP. Hasil penelitian menunjukkan bahwa lahan pertanaman kakao di Desa Penyandingan masuk kedalam kelas kesesuaian lahan cukup sesuai dengan faktor pembatas C-organik (S2nr), dan

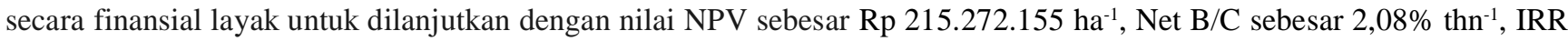
sebesar 25\% thn ${ }^{-1}$, dan BEP (titik impas) akan dicapai pada tahun ke 14, bulan ke 5, hari ke 26.
\end{abstract}

Kata kunci : Kesesuaian lahan, kualitatif, kuantitatif, kelayakan finansial, kakao

\section{PENDAHULUAN}

Pengembangan komoditi perkebunan menempati prioritas tinggi dalam pembangunan bidang ekonomi di Provinsi Lampung, karena diharapkan sebagai penggerak perekonomian masyarakat dan sebagai salah satu sub sektor penghasil devisa melalui kegiatan ekspor komoditas perkebunan. Kakao merupakan salah satu komoditas perkebunan unggulan Provinsi Lampung yang tersebar hampir diseluruh Kabupten, salah satunya Kabupaten Pesawaran. Tahun 2012 Produktivitas tanaman kakao pada daerah Pesawaran mencapai 1006 $\mathrm{kg} \mathrm{ha}^{-1}$. Produksi ini dihasilkan dari perkebunan rakyat, perkebunan swasta (Direktorat Jendral Perkebunan, 2011).

Desa penyandingan merupakan salah satu desa yang berada di Kecamatan Punduh Pidada, yang terletak pada ketinggian $142 \mathrm{~m}$ dpl, dengan rata-rata suhu udara $28{ }^{\circ} \mathrm{C}$. Tipe iklim basah dengan curah hujan $1.500-$ $2.868 \mathrm{~mm} / \mathrm{th}$, kandungan C-organik $0,83 \%$, dan kejenuhan basa 39,615\% (BP3K Punduh Pidada, 2012). Menurut BPS (2012), produktivitas tanaman kakao di Kecamatan Punduh Pidada merupakan produktivitas yang terendah diantara Kecamatan lainnya yang berada di Pesawaran, yaitu sebesar 500,78 $\mathrm{kg} \mathrm{ha}^{-1}$, sedangkan produktivitas tertinggi terdapat di Kecamatan Padang Cermin, yaitu sebesar 1194,59 $\mathrm{kg} \mathrm{ha}^{-1}$. Berdasarkan permasalahan dan potensi yang ada maka perlu dilakukan suatu kegiatan untuk mengetahui kualitas sifat fisik dan kimia tanah serta menduga potensi lahan tersebut agar dapat dimanfaatkan sebagai lahan pengembangan tanaman kakao.

Hasil evaluasi lahan menggambarkan kesesuaian lahan untuk berbagai keperluan dan dapat diketahui hambatan dan kebutuhan biaya dalam pemanfaatan sumber daya lahan tersebut. melalui evaluasi lahan akan dapat diprediksi berapa besar keuntungan dan bahkan kemungkinan kerugian yang didapat, baik secara fisik maupun secara sosial ekonomi (Mahi, 2005). Penelitian ini bertujuan untuk mengevaluasi kesesuaian lahan kualitatif dan kuantitatif pertanaman kakao di Kelompok Tani Sumber Rezeki Desa Penyandingan, Kecamatan Punduh Pidada Kabupaten Pesawaran.

\section{BAHAN DAN METODE}

Penelitian dilaksanakan pada pertanaman kakao di Kelompok Tani Sumber Rezeki Desa Penyandingan, 
Kecamatan Punduh Pidada Kabupaten Pesawaran dengan luas areal 8 ha. Penelitian dilaksanakan pada bulan Juni 2013. Adapun alat dan bahan yang digunakan dalam penelitian ini antara lain, bor tanah, buku munsell soil color chart, GPS, meteran, kantung plastik, pisau dan alat-alat laboratorium. Bahan-bahan yang digunakan dalam adalah contoh tanah dan bahan-bahan kimia untuk analisis tanah di laboratorium.

Penelitian ini dilakukan dengan menggunakan metode survei dengan pendekatan evaluasi lahan secara paralel yaitu melakukan analisis kesesuaian lahan kualitatif dan kuantitatif secara bersamaan. Analisis kualitatif dilakukan dengan cara membandingkan karakteristik lahan dengan persyaratan penggunaan lahan untuk tanaman kakao dan analisis kuantitatif dilakukan dengan menilai Net Present Value (NPV), Net Beneffit Cost Ratio (Net B/C), Internal Rate of Return (IRR), dan Break Event Point (BEP). Pelaksanaan survei dilakukan bertahap yaitu: tahap persiapan, pengumpulan data, dan analisis data.

Tahap persiapan ini merupakan tahap studi pustaka, yaitu meneliti dan mengkaji sumber-sumber pustaka tentang keadaan lokasi penelitian sehingga memperoleh gambaran umum tentang lokasi penelitian, seperti iklim, dan karakteristik lahan. Pada tahap ini dilakukan survei lapang secara kasar dan penentuan tiga titik pengambilan contoh tanah yang mewakili secara keseluruhan berdasarkan keadaan lapang.

Tahap pengumpulan dan analisis data, data yang dikumpulkan dalam penelitian ini meliputi, data fisik primer, data fisik skunder, dan data ekonomi. Analisis kesesuaian lahan kualitatif dilakukan dengan membandingkan karakteristik lahan dengan persyaratan tumbuh tanaman kakao berdasarkan kriteria Djaenudin dkk (2000). Kemudian untuk analisis kesesuaian lahan kuantitatif yaitu dengan mengetahui tingkat kelayakan finansial usaha tani karet dilakukan analisis NPV, Net B/C, IRR, dan BEP (Ibrahim, 2003).

\section{HASIL DAN PEMBAHASAN}

Kesesuaian Lahan Kualitatif. Berdasarkan hasil penelitian yang telah dilakukan pada lahan pertanaman kakao baik secara langsung di lapang maupun analisis di laboratorium, setelah dicocokkan berdasarkan kriteria Djaenudin dkk. (2000), maka didapat faktor pembatas berupa C-organik yang masuk ke dalam kelas kesesuaian lahan cukup sesuai (S2nr). Rendahnya Corganik didaerah penelitian dapat disebabkan oleh beberapa faktor, antara lain yaitu rendahnya pemberian bahan organik dan kemiringan lereng. Faktor pembatas ini dapat diatasi dengan pemberian bahan organik secara cukup dan konservasi tanah. Bahan organik adalah bagian dari tanah yang merupakan suatu sistem kompleks dan dinamis, yang bersumber dari sisa tanaman dan atau binatang yang terdapat di dalam tanah yang terus menerus mengalami perubahan bentuk, karena dipengaruhi oleh faktor biologi, fisika, dan kimia. Bahan organik memiliki peran penting dalam menentukan kemampuan tanah untuk mendukung tanaman, sehingga jika kadar bahan organik tanah menurun, kemampuan tanah dalam mendukung produktivitas tanaman juga menurun (Brady dkk., 2008).

Menurut Sandrawati (2007), penambahan pupuk hijau, sisa-sisa tanaman dan pupuk kandang berpengaruh nyata terhadap kandungan C-organik tanah. Hal ini disebabkan karena bahan organik (pupuk kandang) di dalam tanah akan diurai oleh mikroorganisme tanah yang memanfaatkannya sebagai sumber makanan dan energi menjadi humus, sehingga dengan banyaknya bahan organik yang diberikan maka akan semakin tinggi nilai C-organik tanah. Hal ini sesuai dengan pendapat Soepardi (1983), bahwa tinggi atau rendahnya C-organik tanah dipengaruhi oleh banyaknya bahan organik yang ditambahkan.

Pemberian bahan organik guna meningkatkan kandungan C-organik telah diterapkan oleh beberapa petani di lahan penelitian, namun pemberian bahan organik tersebut belum memberikan perbedaan yang nyata terhadap pertumbuhan dan produktivitas kakao, hal ini disebabkan karena bahan organik yang digunakan masih mempunyai nisbah $\mathrm{C} / \mathrm{N}$ yang tinggi, sehingga diperlukan upaya dalam menurunkan nisbah $\mathrm{C} / \mathrm{N}$ melalui proses pengomposan (Musnamar, 2008).

Pengomposan merupakan suatu teknik pengolahan limbah padat yang mengandung bahan organik biodegradable (dapat diuraikan mikroorganisme). Mengingat peranan bahan organik yang begitu besar terhadap perbaikan fisik, kimia, dan biologi tanah, maka bahan organik (pupuk kandang) yang telah dikomposkan perlu diberikan dalam jumlah banyak (Yuwono, 2005).

Proses pengomposan akan berlangsung sekitar dua sampai tiga minggu. Pada saat proses pengomposan, suhu akan meningkat sehingga bahan menjadi hangat yang menandakan proses berjalan dengan baik. Kompos yang sudah matang memiliki ciri berwarna gelap atau cokelat kehitaman, gembur, dingin, dan sudah tidak mengeluarkan bau. Kompos ini selanjutnya siap digunakan untuk memupuk tanaman (Murbandono, 2006). Selain itu faktor yang mempengaruhi rendahnya kandungan C-organik di daerah penelitian adalah kemiringan lereng. Kemiringan lereng dapat menyebabkan terjadinya erosi tanah, hal ini yang 
mengakibatkan terjadinya leaching atau pencucian yang mengakibatkan kehilangan unsur hara karena terbawa oleh air turun ke tanah yang paling bawah sehingga unsur hara tidak dapat diserap oleh akar tanaman. Kemiringan lereng di lahan penelitian mencapai kemiringan 6,86\%, hal ini berpotensi terjadinya erosi meskipun erosi yang dihasilakn relatif rendah. Untuk mengatasi terjadinya leaching atau pencucian hara dan erosi dapat dilakukan metode konservasi tanah.

Konservasi tanah adalah penempatan setiap bidang tanah pada cara penggunaan yang sesuai dengan kemampuan tanah tersebut dan memperlakukannya sesuai dengan persyaratan yang diperlukan agar tidak terjadi kerusakan tanah. Konservasi terbagi menjadi tiga, yaitu konservasi vegetatif, mekanik dan kimia (Rusdi,2013).

Pada lahan penelitian sebaiknya menggunakan metode konservasi mekanik salah satunya dengan pembuatan rorak. Hasil penelitian Monde (2010) menunjukkan bahwa lahan kakao yang diberi bangunan rorak menghasilkan erosi lebih rendah dibandingkan dengan kontrol. Brata (1998) mengemukakan bahwa semakin pendek jarak antar guludan/rotak pada lereng yang sama, semakin efektif menekan erosi dan aliran permukaan. Pembangunan teras gulud/rorak akan semakin efektif menekan erosi bila jarak antar guludan $4 \mathrm{~m}$ pada lereng $<8 \%$ yang dikombinasikan dengan pemberian mulsa (Subekti, 2006; Lubis, 2004). Tampak bahwa semakin dewasa tanaman kakao, erosi yang dihasilkan semakin menurun, hal ini terjadi karena semakin banyaknya tumpukan serasah yang dihasilkan oleh tanaman kakao. Kelas kesesuaian lahan untuk tanaman kakao di lokasi penelitian selengkapnya tertera pada Tabel 1.

Kelas kesesuaian lahan kuantitatif :

\section{Biaya Produksi}

Biaya produksi yang dikeluarkan petani untuk usaha tani tanaman kakao terdiri dari biaya tetap dan biaya variabel. Biaya tetap adalah biaya yang besar kecilnya tidak tergantung pada produksi yang dihasilkan, dan penggunannya tidak habis dalam satu kali masa produksi. Biaya tetap terdiri dari pajak tanah dan peralatan. Biaya variabel adalah biaya yang besar kecilnya sangat tergantung pada skala produksi. Biaya variabel terdiri dari bibit, pupuk, dan tenaga kerja.

\section{Produksi dan Penerimaan}

Tanaman kakao di Kelompok Tani Sumber Rezeki mulai berproduksi pada tahun ketiga. Rata-rata produksi kakao $1.070 \mathrm{~kg} \mathrm{ha}^{-1}$ selama 24 tahun. Data produksi tanaman kakao tahun ke-1 sampai dengan tahun ke-21 merupakan data sebenarnya. Sedangkan data dari tahun ke-22 sampai tahun ke-24 merupakan data perkiraan yang diperoleh dari persamaan kuadratik $\mathrm{Y}=-$ $8,721 x^{2}+239,4 x-230,8$. Penerimaan petani diperoleh dari penjualan biji kakao dengan harga yang bervariasi, tergantung harga kakao di lokasi. Total penerimaan ratarata yaitu Rp 17.406.376 ha ${ }^{-1}$. Harga kakao tahun ke-1 sampai dengan tahun ke-21 merupakan data sebenarnya. Sedangkan data dari tahun ke-22 sampai tahun ke-25 merupakan data perkiraan yang diperoleh dari persamaan linier $Y=717,4 x+6684$.

Untuk mengetahui tingkat kelayakan usahatani tanaman kakao digunakan analisis NPV, Net B/C, IRR dan BEP. Tingkat suku bunga yang digunakan diasumsikan adalah 15\%. Dari hasil pengolahan data, diperoleh nilai NPV (Tahun pertama s/d tahun ke-24) sebesar Rp 215.272.155 ha ${ }^{-1}$ yang berarti bahwa selama umur 24 tahun usahatani tanaman kakao akan memberikan nilai pendapatan bersih sebesar Rp 215.272.155 $\mathrm{ha}^{-1}$. Nilai Net B/C yang diperoleh adalah $2,08 \% \mathrm{thn}^{-1}$, nilai IRR yang didapat adalah sebesar $25 \%$ thn $^{-1}$ (lebih besar dari tingkat suku bunga yang diasumsikan yaitu $15 \%$ thn $^{-1}$ ). Nilai BEP atau titik impas dimana $T R=T C$ (Total Pendapatan = Total Biaya) dari hasil perhitungan diperoleh hasil bahwa usahatani tanaman kakao di Kelompok Tani Sumber Rezeki Desa Penyandingan Kabupaten Pesawaran akan mencapai titik impas (pengembalian biaya modal dan biaya-biaya lainnya) akan dicapai selama 14 tahun 5 bulan 26 hari. Sehingga usahatani tanaman kakao di lokasi penelitian memberikan keuntungan dan layak untuk dikembangkan.

\section{KESIMPULAN}

Berdasarkan hasil penelitian yang telah dilakukan dapat disimpulkan bahwa kelas kesesuaian lahan pada sebagian lahan pertanaman kakao (Theobroma cacao L) di Kelompok Tani Sumber Rezeki Desa Penyandingan, Kecamatan Punduh Pidada Kabupaten Pesawaran adalah cukup sesuai dengan faktor pembatas C-organik (S2nr). Usaha budidaya tanaman kakao (Theobroma cacao L) di Kelompok Tani Sumber Rezeki Desa Penyandingan, Kecamatan Punduh Pidada Kabupaten Pesawaran secara finansial menguntungkan dan layak untuk dilanjutkan. Hal ini dibuktikan dari hasil perhitungan, nilai $N P V$ sebesar Rp 215.272.155 ha $^{-1}$, Net B/C ratio sebesar 2,08 thn ${ }^{1}$, IRR sebesar $25 \%$ thn $^{-1}$ dan BEP 14 tahun 5 bulan 26 hari. 
Tabel 1. Kelas kesesuaian lahan untuk tanaman kakao di Kelompok Tani, Sumber Rezeki Desa Penyandingan Kecamatan Punduh Pidada Kabupaten Pesawaran.

\begin{tabular}{|c|c|c|c|c|}
\hline No & Karakteris tik Lahan & Nilai & Kela & ahan \\
\hline 1 & $\begin{array}{l}\text { Temperatur }(\text { tc }) \\
\text { Suhu tahunan rata-rata }\left({ }^{\circ} \mathrm{C}\right)\end{array}$ & 26,8 & $\mathrm{~S} 1$ & S1 \\
\hline 2 & $\begin{array}{l}\text { Ketersediaan air (wa) } \\
\text { Curah hujan }(\mathrm{mm}) \\
\text { Lamanya masa kering (bln) } \\
\text { Kelembaban }(\%)\end{array}$ & $\begin{array}{l}1.515 \\
2 \\
57,7\end{array}$ & $\begin{array}{l}\text { S1 } \\
\text { S1 } \\
\text { S1 }\end{array}$ & $\mathrm{S} 1$ \\
\hline 3 & $\begin{array}{l}\text { Ketersediaan Oksigen (oa) } \\
\text { Drainase }\end{array}$ & Baik & $\mathrm{S} 1$ & S1 \\
\hline 4 & $\begin{array}{l}\text { Media perakaran }(\mathrm{rc}) \\
\text { 1. Tekstur } \\
\text { 2. B ahan ka sar }(\%) \\
\text { 3. Kedalaman tanah }(\mathrm{cm})\end{array}$ & $\begin{array}{l}\text { Halus } \\
0 \\
>120\end{array}$ & $\begin{array}{l}\text { S1 } \\
\text { S1 } \\
\text { S1 }\end{array}$ & S1 \\
\hline 5 & $\begin{array}{l}\text { Retensi hara }(\mathrm{nr}) \\
\text { 1. KTK liat }\left(\mathrm{cmolc} \mathrm{kg}^{-1}\right) \\
\text { 2. Kejenuhan basa }(\%) \\
\text { 3. } \mathrm{pH} \mathrm{H}_{2} \mathrm{O} \\
\text { 4. C-organik }(\%)\end{array}$ & $\begin{array}{c}17,99 \\
46,20 \\
6,07 \\
1,3\end{array}$ & $\begin{array}{l}\text { S1 } \\
\text { S1 } \\
\text { S1 } \\
\text { S2 }\end{array}$ & S2 \\
\hline 6 & Toksisitas & & & S1 \\
\hline 7 & $\begin{array}{l}\text { Salinitas } \\
\text { Sodis it as (xn) } \\
\text { Alkal in itas/ESP (\%) }\end{array}$ & $\begin{array}{c}<1,1 \\
-\end{array}$ & $\begin{array}{c}\text { S1 } \\
-\end{array}$ & S1 \\
\hline 8 & $\begin{array}{l}\text { Bahaya sulfudik } \\
\text { Kedalaman sulfudik }(\mathrm{cm})\end{array}$ & $>125$ & $\mathrm{~S} 1$ & S1 \\
\hline 9 & $\begin{array}{l}\text { Bahaya erosi (eh) } \\
\text { 1. Lereng (\%) } \\
\text { 2. B ahaya erosi }\end{array}$ & $\begin{array}{c}6,86 \\
\mathrm{Sr}\end{array}$ & $\begin{array}{l}\text { S1 } \\
\text { S1 }\end{array}$ & S1 \\
\hline 10 & $\begin{array}{l}\text { Bahaya banjir (fh) } \\
\text { Genangan }\end{array}$ & F0 & $\mathrm{S} 1$ & S1 \\
\hline 11 & $\begin{array}{l}\text { Penyiapan lahan (lp) } \\
\text { 1. B atuan dipermukaan }(\%) \\
\text { 2. S ing kapan batuan }(\%)\end{array}$ & $\begin{array}{l}0 \\
0\end{array}$ & $\begin{array}{l}\text { S1 } \\
\text { S1 }\end{array}$ & S1 \\
\hline
\end{tabular}

Keterangan $: \mathrm{KKL}=$ Kelas kesesuaian lahan, $\mathrm{Sr}=$ sangat ringan, $\mathrm{F} 0=$ dalam periode satu tahun tidak pernah tertutup banjir untuk waktu 24 jam.

\section{DAFTAR PUSTAKA}

BPS Kabupaten Pesawaran. 2012. Pesawaran Dalam Angka. Biro Pusat Statistik. Gedung Tataan.

BP3K Punduh Pidada. 2012. Profil Kecamatan Punduh Pidada. Pesawaran.
Brady, N.C and R.R. Weil. 2008. The Nature and Properties of soil. 14th edition. Macmillan, New York. 965 hal.

Brata, K.R. 1998. Pemanfaatan jerami padi sebagai mulsa vertikal untuk pengendalian aliran permukaan dan erosi serta kehilangan unsur hara 
dari pertanian lahan kering. J. Ilmu Tanah dan Lingkungan. 1(1): 21-27

Direktorat Jendral Perkebunan. 2011. Statistik Perkebunan Indonesia. Jakarta : Departemen Kehutanan.

Djaenudin, D., H Marwan, A Hidayat, dan H. Subagyo, A Mulyani, dan N Suharta. 2000. Kriteria Kesesuaian Lahan Untuk Komoditas Pertanian. Departemen Pertanian. 264 hlm.

Ibrahim, Y. 2003. Studi Kelayakan Bisnis. Rineka Cipta. Jakarta. 249 hlm.

Komarudin, N. 2008. Penilaian tingkat bahaya erosi di Sub Daerah Aliran Sungai Cileungsi Bogor. Jurnal Agrikultura. 19 (3): 173-178

Lubis, A. 2004. Pengaruh modifikasi sistem microcatchment terhadap aliran permukaan, erosi serta pertumbuhan dan produksi kacang tanah pada pertanian lahan kering. (Skripsi). Departemen Ilmu Tanah dan Sumber Daya Lahan, Faperta IPB

Mahi, A.K. 2005. Evaluasi dan Perencanaan Penggunaan Lahan. (Diktat, tidak dipublikasikan). Fakultas Pertanian. Universitas Lampung. Bandar Lampung. $240 \mathrm{hlm}$.
Monde, A. 2010. Pengendalian aliran permukaan dan erosi pada lahan berbasis kakao di DAS Gumbasa, Sulawesi Tengah. Jurnal Agrotek Universitas Tadulako Palu. 3(2): 131-136.

Murbandono. 2008. Membuat Kompos. Penebar Swadaya. Jakarta. $54 \mathrm{hlm}$.

Sandrawati, A. 2007. Pengaruh kompos sampah kota dan pupuk kandang terhadap sifat kimia tanah. $J$. Ilmu tanah Universitas Padjajaran. 14 (251): 37-38.

Soepardi, G. 1983. Sifat dan Ciri Tanah. Fakultas Pertanian Institut Pertanian Bogor. Bogor.

Subekti, M 2006. Modifikasi mikro catchment untuk menanggulangi aliran permukaan di lahan kering berlereng. (Skripsi). Departemen Ilmu Tanah dan Sumberdaya Lahan. Fakultas Pertanian, Institut Pertanian Bogor.

Yuwono, D. 2005. Kompos. Penebar Swadaya. Jakarta. $92 \mathrm{hlm}$. 